\title{
Patient access to orphan drugs in France
}

\author{
Marion Bourdoncle ${ }^{1 *}$, Blandine Juillard-Condat ${ }^{1,2,3}$ and Florence Taboulet ${ }^{2,3}$
}

\begin{abstract}
Background: Since incentives were introduced to promote orphan drugs in Europe, several dozens of drugs have been registered at the European level. However, patient access on a national level remains very heterogeneous across Europe. This can be explained by healthcare organization and drug reimbursement, which are within the purview of each Member State. We studied access to orphan drugs in France from the patients' point of view, including marketing but also ease of supply from patients' perspective, financial and time-based dimensions.

Results: We identified 91 registered orphan drugs in Europe, corresponding to 115 orphan drug-therapeutic indication pairs. In France, 78.3\% (90/115) of these pairs were marketed: 100\% were available to inpatients and 75.6\% were available to outpatients. The median period between granting of the European marketing authorization and publication of the reimbursement decision was 360 days. The broadest availability - through community pharmacies - was guaranteed in only $31.1 \%$ of cases. Prescriptions were mainly restricted either to hospital-based doctors or to specialists. Inpatients were not financially responsible for these prescriptions and $72 \%$ of the orphan drug-therapeutic indication pairs available to outpatients were fully covered by national health insurance in France.

Conclusions: Patient access to orphan drugs is not universal in France. Access to reimbursement has a strong impact on patients' effective access to orphan drugs, which may be restricted by difficulties with assessing the clinical value of these drugs and with pricing issues. Prescribing restrictions and drug delivery systems influence the ease of patients' supply for reimbursed orphan drugs for patients. Patients do not seem to be limited by financial issues, but the growing budgetary impact of orphan drugs is worrisome from a societal point of view.
\end{abstract}

Keywords: Orphan drugs, Rare disease, Patient access, Availability

\section{Introduction}

Rare diseases affect around 30 million people in the European Union (EU) and many of them are life-threatening [1]. To encourage the development of orphan drugs, the EU implemented a specific policyRegulation (EC) No. 141/2000-in 2000. Largely inspired by the US Orphan Drug Act, it provides a set of incentives to promote the development and marketing of drugs for serious and rare diseases lacking a satisfactory therapeutic alternative. Drugs are designated as orphan drugs during the development process. Then, they are evaluated to obtain European marketing authorization (MA). Since 2000, several dozen orphan drugs have been registered through a centralized procedure.

In 2010, the European Organization for Rare Diseases (EURORDIS) studied the market access of 60 approved

\footnotetext{
* Correspondence: bourdoncle.m@chu-toulouse.fr

${ }^{1}$ Department of pharmacy, CHU de Toulouse, 293 chemin de Tucaut, 31270

Cugnaux, France

Full list of author information is available at the end of the article
}

orphan drugs (i.e. drugs with an orphan designation and a MA) in 10 EU countries. In France, 90\% of these drugs were available but this proportion was reduced to $33 \%$ in some of the countries studied [2]. The results of EURORDIS study also show that orphan drugs for the rarest diseases were the least accessible, and that accessibility was not just a question of time: for each orphan drug, there was no progress in availability across EU after the first 2 years following MA. In spite of a common European desire to promote orphan drugs, national access for patients is still very heterogeneous across Europe [3] and represents a real public health issue. MA ensures regulatory market access but is not synonymous with effective access. To evaluate patients' effective access to orphan drugs, four dimensions must be considered: availability of the drug, ease of supply from patients' point of view, level of reimbursement and delay between MA and effective access to the drug. As healthcare organization and drug reimbursement by a national health insurance scheme are within the purview of each

(c) The Author(s). 2019 Open Access This article is distributed under the terms of the Creative Commons Attribution 4.0 International License (http://creativecommons.org/licenses/by/4.0/), which permits unrestricted use, distribution, and 
Member State, these four dimensions should be analyzed at national policy level. In this context, an assessment of the four dimensions determining effective access to orphan drugs after MA was conducted in France. All extractions were performed in August 2016.

In France, National Plans for Rare Diseases promote equal access to diagnosis and care throughout the country [4]. In particular, expert physician networks are responsible for ensuring appropriate use of orphan drugs. After MA, reimbursement decisions for each therapeutic indication of orphan and non-orphan drugs are based on the opinion of the French National Authority for Health (Haute Autorité de Santé - HAS). Mandatory criteria for this health technology assessment are actual clinical benefit and clinical added value. The actual clinical benefit is rated on a 4-level scale, and takes into account 5 criteria: severity of the disease/condition, efficacy, adverse effects, intended place in the therapeutic strategy in comparison with other available therapies, and public health benefits. For indications with insufficient actual clinical benefit, the HAS gives a negative opinion for inscription on the list of reimbursed drugs. The final decision of reimbursement is the responsibility of the Ministry of Health. The clinical added value is rated on a 5-level scale, and evaluates comparative efficacy and safety data with regards to available treatments (reference medicinal product or better treatment modalities). In addition, a health economic assessment may be required. Both clinical added value and health economic assessment are criteria used during price negotiation with the pharmaceutical companies. Prescribing and/or dispensing restrictions may limit drug access for safety reasons. Three drug delivery circuits exist: 1) drug dispensing by community pharmacies to outpatients, 2) drug dispensing by hospital pharmacies to inpatients and 3) drug dispensing by hospital pharmacies to outpatients (commonly named "retrocession" in France) [5]. Funding mechanisms and rate of reimbursement vary according to drug delivery circuits and HAS opinions. Figure 1 presents a synthetic diagram of French market access for drugs.

In previous studies, accessibility was measured either by market access [2] or by uninterrupted sales within a 1 -year period [3], without specifically identifying the impact of reimbursement and healthcare organization on patient access to orphan drugs. In this study, the assessment of effective access of French patients to orphan drugs is based on four factors: marketing, ease of supply, financial and time-based dimensions. Patients' perspective is adopted for ease of supply and financial dimension.

\section{Material and methods}

The study was performed in August 2016. A list of active "orphan drug-therapeutic indication" pairs was extracted from the community register of orphan drugs [6]. We focused on drugs with both an orphan designation and a MA for the orphan condition. Patient access to orphan drugs was assessed through 4 dimensions:

- effective marketing of the drug, that means availability of the drug on the French market;

- ease of supply from patient perspective, assuming that some prescribing or dispensing restrictions may be barriers to accessibility;

- financial access (funding and rate of reimbursement);

- access time (between MA and publications of decisions relatives to reimbursement and price).

Information on HAS assessments, prescribing restrictions and drug delivery circuits were collected from several French websites and databases: National Drug Safety Agency [7], French National Authority for Health [8], and National Health Insurance [9].

In order to prevent delays in drug access, compassionate use of an orphan drug (through the French temporary licensing system - temporary authorization for use, ATU) is possible before the MA is granted, but was not taken into account in our study. Once the MA is obtained, drugs that previously received an ATU can benefit from a transitional provision (so called post-ATU) that continues to provide access after the MA until the ministerial decision on reimbursement and pricing has been made. During the post-ATU period, access is granted both for inpatients and outpatients, but only from hospital pharmacies. Orphan drugs in the post-ATU period were included in our study.

\section{Results}

Our study identified 91 orphan drugs, corresponding to 115 orphan drug-therapeutic indication pairs; $16.5 \%$ $(15 / 91)$ of identified drugs were registered in more than one designated orphan condition. Results are summarized in Table 1.

\section{Evaluation by the French National Authority for health (HAS)}

At the time of the study, a published HAS opinion was available for $94 / 115$ (81.7\%) identified orphan drugtherapeutic indication pairs. Among the 94 pairs with a published HAS opinion, only 4 had a negative opinion for reimbursement, based on an insufficient actual clinical benefit. A major or important clinical added value was recognized to $18 / 94$ (19.1\%) pairs. The median period between the granting of the MA and the adoption of the HAS opinion was 227 days. An additional health economic assessment was required for 12 orphan drugtherapeutic indication pairs. 


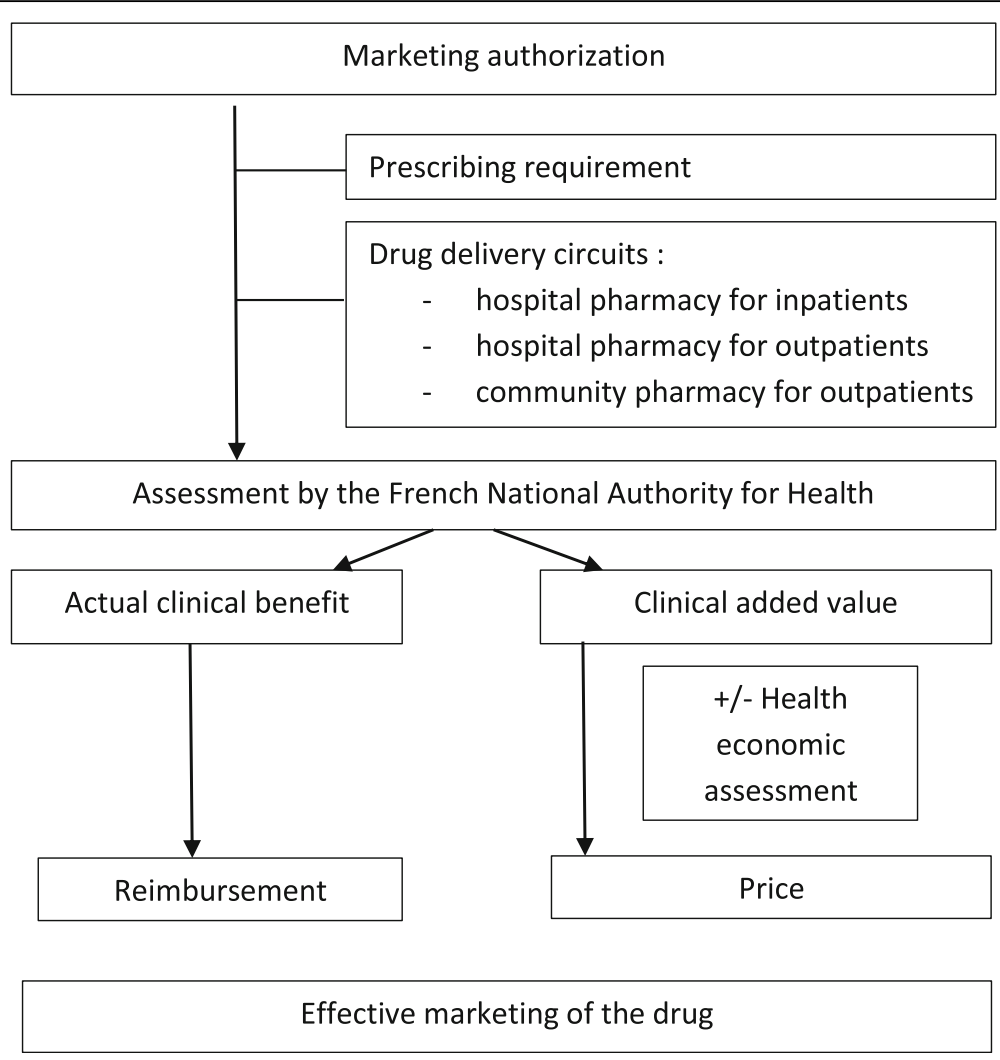

Fig. 1 Synthetic diagram of the market access in France

\section{Market access}

Overall, 78.3\% (90/115) of the orphan drug-therapeutic indication pairs approved in Europe were available to patients in France. The median period between the granting of the European MA and French access to the reimbursed drug market (i.e. publication of ministerial decisions) was 360 days.

Compassionate use (i.e. ATU) had provided access before the MA for 55/115 of the studied orphan drug-therapeutic indication pairs. At the time of our study, 15/90 (16.7\%) orphan drug-therapeutic indication pairs were available through the post-ATU transitional provision.

Concerning the 25/115 (21.7\%) orphan drug-therapeutic indication pairs with active MA and orphan designation that were not marketed in France (Fig. 2):

- 17/25 (68.0\%) had no evaluation available on the HAS website. The reasons identified for the lack of HAS opinion was: assessment in progress as reported on the HAS website (1/17), withdrawal of pharmaceutical company request (1/17), assessment may be ongoing at the time of the study (11/17) and no explanation for the remaining 4/17;
- 4/25 (16\%) were not included in the list of reimbursed medicines at the time of the study despite HAS positive opinions published respectively in December 2004 [1], March 2014 [1] and February 2016 [2]. For the last two, pricing negotiation may be ongoing at the time of the study;

- 4/25 (16\%) were negatively evaluated by the HAS, and none of them was included in the list of reimbursed medicines.

These results allow to hypothesize that the lack of availability of an orphan drug on French market can be explained by:

- factors related to health technology assessment delays $(14 / 25)$ or results (4/25), representing globally $72 \%(18 / 25)$ of cases;

- factors probably related to industrial strategies $(7 / 25)$ for $28 \%$ of cases.

\section{Prescribing restrictions}

The use of orphan drug-therapeutic indication pairs was regulated: $21.1 \%$ (19/90) were reserved for hospital use, $61.1 \%$ (55/90) required specific monitoring, 62.2\% (56/ 
Table 1 Orphan drugs in France in August 2016

\begin{tabular}{|c|c|c|}
\hline & Number & Percen \\
\hline \multicolumn{3}{|l|}{ Active MA and orphan designation } \\
\hline Number of drugs & 91 & - \\
\hline \multicolumn{3}{|l|}{ Number of active designated orphan indications by drug } \\
\hline-1 rare disease & $76 / 91$ & 83.5 \\
\hline-2 rare diseases & $10 / 91$ & 11.0 \\
\hline - 3 rare diseases & $3 / 91$ & 3.3 \\
\hline-4 rare diseases & $1 / 91$ & 1.1 \\
\hline-6 rare diseases & $1 / 91$ & 1.1 \\
\hline Total number of orphan drug-therapeutic indication pairs & 115 & - \\
\hline \multicolumn{3}{|l|}{ Assessment of orphan drug-therapeutic indication pairs $(N=115)$ by the HAS } \\
\hline Number of assessed orphan drug-therapeutic indication pairs (i.e. published HAS opinions) & $94 / 115$ & 81.7 \\
\hline Not found on the HAS website & $18 / 115$ & 15.7 \\
\hline Assessment is on-going & $2 / 115$ & 1.74 \\
\hline Withdrawn by pharmaceutical company & $1 / 115$ & 0.90 \\
\hline \multicolumn{3}{|l|}{ Actual clinical benefit of published HAS opinions } \\
\hline - Important & $72 / 94$ & 76.6 \\
\hline - Moderate & $17 / 94$ & 18.1 \\
\hline - Mild & $1 / 94$ & 1.1 \\
\hline - Insufficient (not accepted for reimbursement) & $4 / 94$ & 4.3 \\
\hline \multicolumn{3}{|l|}{ Clinical Added Value of published HAS opinions } \\
\hline - Major & $2 / 94$ & 2.1 \\
\hline - Important & $16 / 94$ & 17.0 \\
\hline - Moderate & 20/94 & 21.3 \\
\hline - Minor & $36 / 94$ & 38.3 \\
\hline - No clinical improvement & $16 / 94$ & 17.0 \\
\hline - Not applicable (because of insufficient actual clinical benefit) & $4 / 94$ & 4.3 \\
\hline Eligibility for health economic assessment & $12 / 115$ & $-{ }^{a}$ \\
\hline Adopted efficiency opinions & $3 / 12$ & 25.0 \\
\hline - with major methodological criticisms expressed by the HAS & $2 / 3$ & 66.7 \\
\hline Published efficiency opinion & $1 / 3$ & 33.3 \\
\hline \multicolumn{3}{|l|}{ Marketing of registered orphan drug-therapeutic indication pairs } \\
\hline Number of marketed orphan drug-therapeutic indication pairs & $90 / 115$ & 78.3 \\
\hline - through the post-ATU transitional provision & $15 / 90$ & 16.7 \\
\hline Number of non-marketed orphan drug-therapeutic indication pairs & $25 / 115$ & 21.7 \\
\hline \multicolumn{3}{|l|}{ Regulatory prescribing requirements of marketed orphan drug-therapeutic indication pairs $(N=90)$} \\
\hline Reserved for hospital use & $19 / 90$ & 21.1 \\
\hline On hospital prescription & $56 / 90$ & 62.2 \\
\hline On initial hospital prescription & $14 / 90$ & 15.6 \\
\hline On specialist doctor's prescription & $60 / 90$ & 66.7 \\
\hline Specific monitoring & $55 / 90$ & 61.1 \\
\hline \multicolumn{3}{|l|}{ Drug delivery circuits for marketed orphan drug-therapeutic indication pairs ( $N=90)$} \\
\hline Hospital pharmacies for inpatients & $90 / 90$ & 100 \\
\hline - through the post-ATU transitional provision & $15 / 90$ & 16.7 \\
\hline Community pharmacies & $28 / 90$ & 31.1 \\
\hline
\end{tabular}


Table 1 Orphan drugs in France in August 2016 (Continued)

\begin{tabular}{|c|c|c|}
\hline & Number & Percent \\
\hline Hospital pharmacies for outpatients (retrocession) & $40 / 90$ & 44.4 \\
\hline - through the post-ATU transitional provision & $13 / 40$ & 32.5 \\
\hline \multicolumn{3}{|l|}{ Funding / theoretical reimbursement ratesss } \\
\hline Inpatients (hospital) & - & - \\
\hline - universal reimbursement (in connection with Diagnosis Related Groups) & $52 / 90$ & 57.8 \\
\hline - high-priced drug list & $23 / 90$ & 25.5 \\
\hline - specific to the post-ATU transitional provision & $15 / 90$ & 16.7 \\
\hline Outpatients (hospital pharmacies) $=$ retrocession & - & - \\
\hline - full reimbursement (100\%) & 33/40 including 13 post-ATU & 82.5 \\
\hline - reimbursement up to $65 \%$ & $6 / 40$ & 15.0 \\
\hline \multirow[t]{2}{*}{ - reimbursement up to $30 \%$} & & 2.5 \\
\hline & $1 / 40$ & \\
\hline Community pharmacies & - & - \\
\hline - full reimbursement (100\%) & $16 / 28$ & 57.1 \\
\hline - reimbursement up to $65 \%$ & $9 / 28$ & 32.1 \\
\hline - reimbursement up to $30 \%$ & $3 / 28$ & 10.7 \\
\hline
\end{tabular}

${ }^{a}$ Not applicable because health economic evaluations were set up in France in October 2012 [53]

90) were available only on hospital prescription, $15.6 \%$ (14/90) were available only on initial hospital prescription. Prescriptions were restricted to some specialist doctors for $66.7 \%(60 / 90)$ of them.

\section{Access facility from patients' perspective}

Orphan drugs were mostly managed in hospitals: $68.9 \%$ $(62 / 90)$ were purchased and delivered by hospital pharmacies to inpatients and outpatients. The retrocession mechanism provided outpatients with access to $44.4 \%$ (40/90) of orphan drug-therapeutic indication pairs. Inpatients had access to $100 \%$ (90/90) and outpatients had access to $75.6 \%(68 / 90)$ of orphan drug-therapeutic indication pairs. The broadest access (i.e. through community pharmacies) was guaranteed in $31.1 \%$ (28/90) of cases.

\section{Financial access}

No financial contribution for orphan drugs was requested for inpatients. For outpatients (through both the retrocession circuit and community pharmacies), $72 \%$ $(49 / 68)$ of orphan drug-therapeutic indication pairs were fully reimbursed. However, $22.1 \%$ (15/68) of the

\section{$25 / 115(21.7 \%)$ " orphan drug - therapeutic indication » pairs were not marketed in France}

$17 / 25(68.0 \%)$ for whom no evaluation had been found on the HAS website

- 1 was being assessed by the HAS (as reported on the HAS website)

- 1 for whom the HAS assessment request had been withdrawned by the pharmaceutical company

- 11 obtained their MA from December 2015 (i.e. the HAS assessment may be ongoing)

- 4 without explanation: 3 obtained their MA between 2014 and August 2015 and 1 obtained its MA in July 2009

4/25 (32.0\%) had a positive published HAS opinion

- 2 had a HAS positive opinion published from February 2016 (i.e. pricing negotiations may be ongoing)

- 1 had a HAS positive opinion published in March 2014

- 1 had a HAS positive opinion published in December 2004

4/25 (16.0\%) had a negative published HAS opinion (insufficient actual benefit) and had, in

consequences, no access to the market of reimbursed drugs

Fig. 2 Assessment of "orphan drug - therapeutic indication" pairs not marketed in France 
orphan drug-therapeutic indication pairs were reimbursed up to 65 and $5.9 \%(4 / 68)$ of them up to $30 \%$.

\section{Discussion}

Orphan drug status has encouraged pharmaceutical investment and hence market access for treating rare and serious diseases [10]. In this manner, the European policy on orphan drugs has fulfilled its objective by making these diseases more attractive from a commercial point of view. However, the main purpose of this policy is to address highly unmet medical needs. The objective of our study was to assess the impact of this European policy by measuring the effective access to orphan drugs from the patients' point of view in France. Our results show that $78.3 \%$ of approved orphan drug-therapeutic indication pairs were marketed, among which only $31.1 \%$ had the broadest availability and $72 \%$ were fully reimbursed for outpatients. Our study was limited to France because of large differences between Member States' policies and health technology assessments [11].

As we focused on registered orphan drugs, our study underestimates the real access to drugs for rare diseases in France. First, drugs registered in rare diseases but that were not designated as orphan drugs were excluded. Then we also excluded drugs with an orphan designation for which the MA application was still in progress, even if they were available through the compassionate use provision (i.e. ATU), which is known to accelerate drug access for patients [12]. Lastly, drugs already marketed for other conditions and available for rare diseases through the temporary recommendation for use (RTU) provision were not taken into account. While these drugs can be used for off-label indications, their use is accompanied by strict data collection requirements. The final goal of this RTU provision is to expand the approved therapeutic indications.

At the time of our study, $78.3 \%$ of the registered orphan drug-therapeutic indication pairs were marketed in France. In a survey conducted and published by EURORDIS in 2010 [2], 90\% of the studied orphan drugs were available in France. Several factors can explain this difference: 1) our study is more recent and more exhaustive; 2) we studied orphan drug-therapeutic indication pairs because reimbursement is granted by therapeutic indication and we hypothesized that reimbursement has a big impact on marketing. A total of $16.5 \%$ of identified orphan drugs were indicated in at least two orphan conditions. However, there is a bias between our theoretical approach and reality: when reimbursement is given for one therapeutic indication, the marketed drug can be used in another non-reimbursed indication based on medical argument for hospital delivery circuits or because validation of the indication is not always required for the community delivery circuit.
For marketed orphan drugs, the median delays measured between MA and HAS opinion, and between MA and ministerial decisions of reimbursement and pricing were consistent with delays reported in another French study conducted on a sample of a hundred of orphan and non-orphan drugs [13]: respectively 227 days versus 184 days between MA and HAS opinion, and 360 days versus 359.5 days between MA and decisions of reimbursement and pricing. The negotiation phase for orphan drug prices could be shorter for two reasons. First, the high clinical added value ensures the price is consistent with European prices. The second reason is the specific French provision of "capping" [14]. For orphan drugs with an annual cost per patient exceeding $€ 50,000$, "in return for the acceptance of a price consistent with international prices, [the pharmaceutical company undertakes] to supply the drug to all patients eligible for treatment, without any restriction, for a total amount of revenue fixed in advance". So access to reimbursement and pricing did not appear to be slowed by the difficulties inherent to the scarcity of therapeutic indications in France.

Table 1 results demonstrate that in France, hospital capabilities are needed for the majority of marketed orphan drugs. These prescribing and dispensing requirements promote the proper use of orphan drugs and careful patient monitoring, while helping regulate healthcare expenditures [15]. It can be noticed orphan drugs are four times more likely to be provided through retrocession than all the brand-name drugs marketed in France (i.e. orphan and non-orphan drugs): retrocession concerns $44.4 \%$ of orphan drugs versus $10.8 \%$ of all drugs marketed in France [16, 17]. This restrictive distribution circuit allows special monitoring of prescriptions and deliveries [18]. Yet better safety should be balanced with restrictions of patients accessibility: according to 2017 statistics of the French chamber of pharmacists, there are 21,815 community pharmacies in France, and only 2445 hospital pharmacies [19]. It should be noticed that $32.5 \%(13 / 40)$ of orphan drug-therapeutic indication pairs subject to retrocession were available through the post-ATU provision. At the end of this transitional period, some of them may be delivered by community pharmacies.

All of the orphan drug-therapeutic indication pairs available to inpatients and $72 \%$ of the pairs available to outpatients were fully covered by the national health insurance scheme in France. For inpatients, funding was either universal (in connection with Diagnosis related groups), or related to extra funding granted to hospitals for high-cost drugs in return for appropriate use, or specific to the post-ATU transitional provision. For outpatients, when there was a theoretical excess to be paid by patients, the actual reimbursement rate could not be 
determined. Indeed, a French policy called Affection Longue Durée 31 (ALD31) exists specifically for serious progressive or disabling illnesses whose treatment is particularly costly and is predicted to last more than 6 months. In this case, the referring physician can ask the national health insurance scheme to fully reimburse all the care and treatments related to the patient's illness. Hence, all orphan drugs can theoretically be reimbursed up to $100 \%$ under an ALD31. From the French patients' point of view, the access to orphan drugs is unlikely to be hampered by financial limitations.

According to our study, $21.7 \%$ of orphan drug-therapeutic indication pairs were not marketed in France. For $72 \%$ of these pairs $(18 / 25)$, a link can be established between the lack of drug availability and health technology assessment process (delays or results). First because access to drug reimbursement is needed for marketing: a negative HAS opinion followed by a negative ministerial decision for reimbursement always result in no marketing of the orphan drug. Hence, the first step for patient access is demonstrating a clinical benefit, which is a mandatory criteria for reimbursement in France. On one hand, clinical data for orphan drugs may be limited, making it difficult to assess the "value" of these drugs [20-22]. On the other hand, the severity of the disease and the lack of satisfactory therapeutic alternatives are elements in favor of orphan drugs. The relative contribution of the drug's role in the therapeutic strategy within the clinical benefit assessment has evolved: considered as low in 2003 [23], it became a determining factor in 2014 [24]. For the 4 orphan drug-therapeutic indications pair concerned in this study, the HAS justified the insufficient actual benefit by a level of evidence considered as too low [25-28].

Then, the second impact of health technology assessment on drug availability is time-based: our study was cross-sectional, but assessment and price negotiation delays must be considered. And lastly, as marketing is a function of business, strategic and commercial choices, pharmaceutical companies can decide not to market a drug if the negotiated prices are not acceptable to them [29]. In general, high levels of clinical added value contribute to better pricing. Orphan drugs are more likely to obtain major or important clinical added value: this proportion is $19.1 \%$ in this study, but reaches $52 \%$ of orphan drugs between 2001 and 2009, versus 32\% of all drugs evaluated during this period [30]. Moreover, payers value rarity in pricing decisions [31]. Between 2000 and 2010, the annual cost per patient treated per orphan drug ranged from $€ 1251$ to $€ 407,631$ (Euro zone + United Kingdom); the median cost was $€ 32,242$ [32]. In our study, most orphan drug-therapeutic indication pairs available to outpatients were fully reimbursed since these orphan drugs were judged irreplaceable and particularly expensive treatments. In France, patients do not seem to be limited by the price of orphan drugs. But the growing budgetary impact of orphan drugs is worrisome from a societal point of view [32, 33].

Drugs claiming a major, important or moderate clinical added value (i.e. 38/94 orphan drug-therapeutic indication pairs in our study) must undergo a health economic assessment if they are expected to have a significant impact on national health insurance expenditures (i.e. annual sales of $€ 20,000,000$ or more [34]). We found that 12 orphan drug-therapeutic indication pairs were slated for a health economic assessment. As a reference, 21 and 23 drugs qualified for a health economic assessment in 2014 and 2015, respectively, all drugs pooled. Major methodological limitations appeared in two efficiency opinions out of the three adopted for orphan drugs. The incremental cost-effectiveness ratio exceeded $€ 230,000 / \mathrm{QALY}$ in the only published efficiency opinion for orphan drugs at the time of our study [35]. A number of researches have suggested that the commonly used health technology assessment methods are poorly suited to rare diseases: it is well known that orphan drugs are usually cost-ineffective, yet restrictions in funding may not be in line with societal preferences $[36,37]$. Other studies aimed to establish societal preferences for funding drugs used to treat orphan diseases, but they have limitations and their results do not show a clear societal preference for prioritizing the treatment of rare diseases [38, 39]. Moreover, equity and ethical questions could influence decision makers [40]. Relationships between level of evidence, effect size, economic logic, ethics and equity are difficult to grasp [41].

France, like many countries, has implemented legislation to support the market access for orphan drugs [42, 43]. However, regulation is essential to ensure the sustainability of orphan drug coverage [44, 45], both at the European level and the Member State level. Since this status provides many development and financial incentives, such as specific market exclusivity, some fear that orphan drugs will become a "good business opportunity" for industry [46]. At the European level, facing the growing number of orphan drugs approved [10], the EMA has started publishing orphan maintenance assessment reports in January 2018 [47]. The objective is to assess whether a drug fulfils the criteria for orphan designation at the time of the MA to reconfirm the eligibility of the status. At the Member State level, criteria chosen for health technology assessments, combined with setting up of specific policies on orphan drugs, resulted in heterogeneity between European countries in patient accessibility to these drugs [48]. Several potential solutions exist to cover the gap between European drug market access and national patient access to licensed drugs. These include early contact between the pharmaceutical 
companies and the health technology assessment agencies and collaboration between the EMA and the national health technologies assessment agencies [49, 50]. In 2016, the European Working Group for Value Assessment and Funding Processes in Rare Diseases (ORPHVAL) developed recommendations to improve the consistency of orphan drugs pricing and reimbursement assessment in Europe [51], which should optimize efficient patient access to orphan drugs in Europe.

\section{Conclusion}

In conclusion, access to reimbursement and prices negotiation have a strong impact on effective patient access to orphan drugs in France. Prescribing restrictions and drug delivery systems influence the ease of patient supply for reimbursed orphan drugs. Patient access to orphan drugs remains incomplete and raises many questions. What is the collective interest of implementing incentives to develop and register these drugs if they are not accessible to all patients?

On one hand, this overview revealed difficulties in evaluating the reimbursement and pricing of orphan drugs. More transparency is needed to reduce the uncertainty for pharmaceutical companies about access to orphan drug reimbursement [52] to maintain their interest in rare and serious conditions. On the other hand, the orphan drug policy was marked by years without incentives followed by years with strong incentives. We believe the time has come to find a compromise in the form of reasonable and controlled incentives.

\section{Abbreviations}

ATU: Autorisation Temporaire d'Utilisation (French temporary licensing system); EU: European Union; EURORDIS: European Organization for Rare Diseases; HAS: Haute Autorité de Santé (French National Authority for Health); MA: Marketing Authorization; QALY: Quality-Adjusted Life Year; RTU: Recommandation Temporaire d'Utilisation

\section{Acknowledgments}

Joanne Archambault, PhD for English editing assistance, and the anonymous reviewers for their comments and suggestions.

\section{Funding}

Not applicable.

\section{Authors' contributions}

$\mathrm{MB}$ analyzed and interpreted the data. MB, BJC and FT were major contributors in writing the manuscript. All authors read and approved the final manuscript.

\section{Ethics approval and consent to participate}

Not applicable.

\section{Consent for publication}

Not applicable.

The datasets analyzed for the current study are available from the corresponding author on reasonable request.

\section{Competing interests}

The authors declare that they have no competing interests.

\section{Publisher's Note}

Springer Nature remains neutral with regard to jurisdictional claims in published maps and institutional affiliations.

\section{Author details}

'Department of pharmacy, CHU de Toulouse, 293 chemin de Tucaut, 31270 Cugnaux, France. ${ }^{2}$ INSERM UMR 1027, Toulouse, 37 allées Jules Guesde, 31000 Toulouse, France. ${ }^{3}$ University of Toulouse III, Toulouse, France.

Received: 12 July 2018 Accepted: 7 February 2019

Published online: 18 February 2019

\section{References}

1. Andriukaitis V. European Rare Diseases Day 2018: One-year anniversary of the European Reference Networks for rare diseases. European Commission, Health and Food Safety Directorate General. 2018. https://ec.europa.eu/ ireland/news/european-rare-disease-day-2018_en. Accessed 24 March 2018.

2. Le Cam Y. Inventory of Access and Prices of orphan drugs across Europe: a collaboration work between national alliances on rare diseases and Eurordis. 2010. https://img2.eurordis.org/newsletter/pdf/mar-2011/ERTC_13122010_ YLeCam_Final.pdf. Accessed 07 Sep 2016.

3. Detiček A, Locatelli I, Kos M. Patient Access to Medicines for Rare Diseases in European Countries. Value in Health. 2018. https://www.sciencedirect. com/science/article/pii/S109830151830189X. Accessed 24 March 2018

4. Chaffotec AL. Trajectoires de soins et facteurs sociodémographiques : l'exemple des maladies rares en France, care path and sociodemographic attributes: the case of rare diseases in France. Journal de gestion et d'économie médicales. 2015;32(5):389-409.

5. Gridchyna I, Aulois-Griot M. La rétrocession de médicaments par les hôpitaux : quels bénéfices pour les acteurs ? Médecine Droit. 2011;110: 203-10.

6. Register of designated Orphan Medicinal Products (by number). 2018. http://ec.europa.eu/health/documents/community-register/html/orphreg. htm. Accessed 24 March 2018.

7. https://ansm.sante.fr/. Accessed 9 November 2018

8. https://www.has-sante.fr/portail/jcms/fc_1249588/fr/accueil. Accessed 9 November 2018.

9. https://Www.ameli.fr/. Accessed 9 November 2018

10. EMA. Orphan Medicines Figures 2000-2017 - WC500185766. 2018. http:// www.ema.europa.eu/docs/en_GB/document_library/Other/2015/04/ WC500185766.pdf. Accessed 14 April 2018.

11. Denis A, Mergaert L, Fostier C, Cleemput I, Simoens S. A comparative study of European rare disease and orphan drug markets. Health Policy Amst Neth. 2010;97(2-3):173-9.

12. Taboulet F. Les " médicaments innovants " destinés aux patients ambulatoires : quelle spécificité en droit français ? Médecine Droit. 2008;93:172-80

13. Polton D. Rapport sur la réforme des modalités d'évaluation des médicaments. 2015. http://solidarites-sante.gouv.fr/IMG/pdf/rapport_ polton_-_evaluation medicaments.pdf. Accessed 14 April 2018.

14. Accord-cadre 2016-2018 entre le Comité économique des produits de santé et les entreprises du médicament (Leem). 31/12/2015. http:// www.snphpu.org/files/Actualites/Accord-cadre-2016-2018.pdf. Accessed 14 April 2018.

15. Aulois-Griot M, Taboulet F. Médecins et pharmaciens face aux médicaments à prescription particulière: entre logiques sanitaires et logiques économiques. Médecine Droit. 2007;84:83-9.

16. Base des médicaments et informations tarifaires. 2016. http://www.codage. ext.cnamts.fr/codif/bdm_it/index_tele_ucd.php?p_site=AMELI. Accessed 21 July 2016.

17. Thériaque.2016. http://www.theriaque.org/apps/contenu/accueil.php. Accessed 21 July 2016

18. Taboulet $F$, Dulin $R$, Bonnin $M$, Saux $M$. La rétrocession hospitalière des médicaments : quel service pharmaceutique rendu au patient ? Exemple de I'Aquitaine. Revue médicale de l'Assurance maladie. 2004;2:101-8.

19. French Chamber of Pharmacists. 2017 annual report. http://www.ordre. pharmacien.fr/Communications/Rapports-d-activite/Rapport-d-activite-2017. Accessed 9 Nov 2018.

20. Joppi R, Bertele' V, Garattini S. Orphan drugs, orphan diseases. The first decade of orphan drug legislation in the EU. Eur J Clin Pharmacol. 2013; 69(4):1009-24. 
21. Kanters TA, de Sonneville-Koedoot C, Redekop WK, Hakkaart L. Systematic review of available evidence on 11 high-priced inpatient orphan drugs. Orphanet J Rare Dis. 2013;8:124.

22. Dupont AG, Wilder PBV. Access to orphan drugs despite poor quality of clinical evidence. Br J Clin Pharmacol. 2011;71(4):488.

23. Le Pen C, Priol G, Lilliu H. What criteria for pharmaceuticals reimbursement? An empirical analysis of the evaluation of " medical service rendered " by reimbursable drugs in France. Eur J Health Econ. 2003;4(1):30-6.

24. Bouvenot $\mathrm{G}$. Les apports et les limites de la notion de service médical rendu. Rev Droit Sanit Soc. 2011;3:403-8.

25. Commission de la Transparence, HAS. Avis de transparence GLYBERA. 2015. http://www.has-sante.fr/portail/upload/docs/evamed/CT-14224_GLYBERA_ PIC_INS_Avis3_CT14224.pdf. Accessed 14 Apr 2018.

26. Commission de la Transparence, HAS. Avis de transparence MEPACT. 2010. http://www.has-sante.fr/portail/upload/docs/application/pdf/2010-12/ mepact-_ct-8306.pdf. Accessed 14 Apr 2018.

27. Commission de la Transparence, HAS. Avis de transparence NEXOBRID. 2015. http://www.has-sante.fr/portail/upload/docs/evamed/CT-14127_ NEXOBRID PIC INS AvisPostAud CT14127.pdf. Accessed 14 Apr 2018.

28. Commission de la Transparence, HAS. Avis de transparence RAXONE. 2016. http://www.has-sante.fr/portail/upload/docs/evamed/CT-14749_RAXONE_ PIC_INS_Avis3_CT14749.pdf. Accessed 14 Apr 2018.

29. Leonard JV, Richmond S. Pricing of orphan drugs. Lancet. 2009:373(9662):462

30. Fauvelle K. Les médicaments orphelins : rétrospective et perspectives du marché européen. 2012. https://hal.archives-ouvertes.fr/hal-00752254v2/ document. Accessed 14 Apr 2018

31. Medic G, Korchagina D, Young KE, Toumi M, Postma MJ, Wille M, et al. Do payers value rarity? An analysis of the relationship between disease rarity and orphan drug prices in Europe. J Mark Access Health Policy. 2017;5(1): 1299665.

32. Schey C, Milanova T, Hutchings A. Estimating the budget impact of orphan medicines in Europe: 2010-2020. Orphanet J Rare Dis. 2011;6:62.

33. Hutchings A, Schey C, Dutton R, Achana F, Antonov K. Estimating the budget impact of orphan drugs in Sweden and France 2013-2020. Orphanet J Rare Dis. 2014;9:22.

34. Décision $n^{\circ} 2013.0111 / D C / S E E S P$ du 18 septembre 2013 du collège de la Haute Autorité de santé relatif à l'impact significatif sur les dépenses de l'assurance maladie déclenchant l'évaluation médico-économique des produits revendiquant une ASMR ou une ASA de niveaux I, II ou III. 2013. https://www.has-sante.fr/portail/upload/docs/application/pdf/2013-09/c 2013_0111_definition_impact_significatif.pdf. Accessed 24 Mar 2018.

35. Commission d'Evaluation Economique et de Santé Publique, HAS. Avis d'efficience ADEMPAS. 2014. https://www.has-sante.fr/portail/upload/docs/ application/pdf/2015-02/adempas_14102014_avis_efficience.pdf. Accessed 24 Mar 2018.

36. Hughes DA, Tunnage B, Yeo ST. Drugs for exceptionally rare diseases: do they deserve special status for funding? QJM. 2005;98(11):829-36.

37. Drummond MF, Wilson DA, Kanavos P, Ubel P, Rovira J. Assessing the economic challenges posed by orphan drugs. Int J Technol Assess Health Care. 2007;23(1):36-42.

38. Mentzakis E, Stefanowska P, Hurley J. A discrete choice experiment investigating preferences for funding drugs used to treat orphan diseases: an exploratory study. Health Econ Policy Law. 2011;6(3):405-33.

39. Desser AS, Gyrd-Hansen D, Olsen JA, Grepperud S, Kristiansen IS. Societal views on orphan drugs: cross sectional survey of Norwegians aged 40 to 67 . BMJ. 2010;341:C4715.

40. Pinxten $W$, Denier $Y$, Dooms M, Cassiman J-J, Dierickx K. A fair share for the orphans: ethical guidelines for a fair distribution of resources within the bounds of the 10-year-old European orphan drug regulation. J Med Ethics. 2012;38(3):148-53.

41. Collège des économistes de la santé. La lettre du collège - Les maladies rares. 2015. http://www.ces-asso.org/sites/default/files/Lettre_du_College_ novembre_2015.pdf. Accessed 14 Apr 2018

42. Simoens $\mathrm{S}$, Cassiman D, Dooms M, Picavet E. Orphan drugs for rare diseases: is it time to revisit their special market access status? Drugs. 2012;72(11): 1437-43.

43. Gammie T, Lu CY, Babar ZU-D. Access to orphan drugs: a comprehensive review of legislations, regulations and policies in 35 countries. PLoS One. 2015;10(10):e0140002.

44. Michel M, Toumi M. Access to orphan drugs in Europe: current and future issues. Expert Rev Pharmacoecon Outcomes Res. 2012;12(1):23-9.
45. Rollet $P$, Lemoine $A$, Dunoyer $M$. Sustainable rare diseases business and drug access: no time for misconceptions. Orphanet J Rare Dis. 2013:8:109.

46. OECD. New health technologies : managing access, value, sustainability [internet]. Paris: OECD Publishing; 2017. http://www.keepeek.com/DigitalAsset-Management/oecd/social-issues-migration-health/managing-newtechnologies-in-health-care_9789264266438-en. Accessed 25 Mar 2018.

47. European Medicines Agency - News and Events - Is an orphan medicine still an orphan once it gets on the market? EMA publishes additional reports on decision-making for orphan medicines; initiative addresses requests from stakeholders. 2018. http://www.ema.europa.eu/ema/index. jsp?curl=pages/news_and_events/news/2018/01/news_detail_002885. jsp\&mid=WC0b01ac058004d5c1. Accessed 25 Mar 2018.

48. Nicod E. Why do health technology assessment coverage recommendations for the same drugs differ across settings? Applying a mixed methods framework to systematically compare orphan drug decisions in four European countries. Eur J Health Econ. 2017;18(6):715-30.

49. Hughes-Wilson W, Palma A, Schuurman A, Simoens S. Paying for the orphan drug system: break or bend? Is it time for a new evaluation system for payers in Europe to take account of new rare disease treatments? Orphanet J Rare Dis. 2012;7:74

50. MoCA-OMP - Working Group on Mechanism of Coordinated Access to Orphan Medicinal Products. Transparent Value Framework, Process on Corporate Social Responsibility in the Field of Pharmaceuticals Platform on Access to Medicines in Europe. Brussels; 2014. https://www.google.fr/url?sa= t\&rct=j\&q=\&esrc=s\&source=web\&cd=3\&ved=0ahUKEwil-57ah7raAhWFchQ KHdeRAu0OFgg4MAl\&url=http\%3A\%2F\%2Feceuropa.eu\%2FDocsRoom\% 2Fdocuments\%2F7631\%2Fattachments\%2F1\%2Ftranslations\%2Fen\%2 Frenditions\%2Fpdf.\&usg=AOvVaw1H2J\%2D\%2D5bcZGsniRwSDx7v9. Accessed 14 Apr 2018.

51. Annemans L, Aymé S, Le Cam Y, Facey K, Gunther P, Nicod E, et al. Recommendations from the European working Group for Value Assessment and Funding Processes in rare diseases (ORPH-VAL). Orphanet J Rare Dis. 2017:12:50.

52. Simoens S. Pricing and reimbursement of orphan drugs: the need for more transparency. Orphanet J Rare Dis. 2011:6:42

53. Décret $n^{\circ}$ 2012-1116 du 2 octobre 2012 relatif aux missions médicoéconomiques de la Haute Autorité de santé. https://www.legifrance.gouv.fr/ affichTexte.do?cidTexte=JORFTEXT000026453514\&categorieLien=id. Accessed 13 Feb 2019
Ready to submit your research? Choose BMC and benefit from:

- fast, convenient online submission

- thorough peer review by experienced researchers in your field

- rapid publication on acceptance

- support for research data, including large and complex data types

- gold Open Access which fosters wider collaboration and increased citations

- maximum visibility for your research: over $100 \mathrm{M}$ website views per year

At BMC, research is always in progress.

Learn more biomedcentral.com/submissions 